\title{
A Study of the Business Model of Tencent Group
}

\author{
Xian-Fa Shang ${ }^{1}$, Myeong-Cheol Choi*², Seung-Jin Kim ${ }^{3}$ \\ ${ }^{1}$ Ph.D.student, Department of Business, Gachon University, S.Korea \\ ${ }^{*}$ Assistant Professor, Department of Business, Gachon University, S.Korea \\ ${ }^{3}$ Ph.D.student, Department of Business, Sogang University, S.Korea \\ shangxianfa@naver.com¹, oz760921@gachon.ac.kr², ${\text { shalomksj@ } \text { hanmail.net }^{3}}^{3}$
}

Article History: Received: 11 January 2021; Accepted: 27 February 2021; Published online: 5 April 2021

\begin{abstract}
With the development of information technology, Many Internet enterprises have emerged rapidly, and to thrive in the face of fierce competition, it is vital for them to have efficient business models. These business models are a popular focus of research interest. At present, there is still no unified interpretation of the business model system of Internet enterprises. The existing theoretical research examines mainly individual enterprises; there are only a very few studies on the business models of platform enterprises. This study therefore aims to summarize the literature on the basis of existing theories combined with the enterprise reality, through a literature review and case study of the Tencent group of companies in China. This study explores the online trading platform for enterprises and its business model.It is instructive to correctly analyze the Internet business model of enterprises in the third party service platform enterprises.
\end{abstract}

Keywords: Internet, Tencent, business model, profit model, value model

\section{Introduction}

In recent decades, many Chinese Internet companies, such as Tencent, Baidu, and Alibaba have achieved high growth. With creative economy as their core concept, they provide information, consulting, entertainment, and other services for consumers. These firms represent the new economy and belong to the emerging information service industry. The business models of such firms attract much attention from the academic and business community. However, prior studies did not explore the essential characteristics of these business models. The problem is that most Internet enterprise business models are vague and undefined, relating basically to increasing profits, and market access[1].In the backdrop of the global economic slowdown, the growth in business model innovation caused by the change in scale of trade has become of vital significance to firms. Business model innovation can lead the enterprise to new market resources, bring new concepts to business development and economic growth, and increase the firm's competitive advantages (e.g., Tencent). Successful cases of business model innovation continue to emerge, which encourages entrepreneurs to constantly pursue business model innovation[2].

With this background, the present study is rooted in theoretical work combined with enterprise reality through a literature review and a case study of the Tencent group in China. This study explores the Tencent online trading platform for enterprises and its business model. In the Internet industry, different business models have become enterprise management strategies for competition in terms of the choice of operational tools. The Internet business model is an important part of enterprise core competitiveness, the method to transition to a new business model. This study aims to provide guidance in terms of other Internet firms' growth potential.

\section{Business model theory}

\subsection{Definition of a business model}

In recent years, there has been a growing understanding of the importance of business models. Studies on business models focus on product, business, company, and multi-aggregate industry levels. business model, in its 
most basic sense, refers to the way of doing business, which is the model on which a company lives -- a model that can bring profits to the enterprise.argue that business models are the means of corporate profitability. The term "business model" first appeared in the 1950s, but did not become popular until the mid-1990s. The Internet and information technology changed the trading rules and methods, brought about continuous innovation and new forms of business methods and transactions, and became the new method, channel, and approach to business competition. In particular, Internet enterprises achieved great success by virtue of business model innovation, creating value that is difficult for traditional enterprises to obtain in the short term, such as Amazon, Alibaba, and Tencent, making business models a new weapon with which enterprises compete against each other[3,15].

\subsection{Business model characteristics}

1) Integrity and systematicity. The model is much more than the sum of its parts, which can reflect the essence of how the enterprise system focuses.A business model that lacks comprehensiveness may well be attractive in one respect, but it may not be possible at all because the entrepreneur ignored the elements that support intrinsic profitability.

2) Innovation. Innovation is a tool with which entrepreneurs can make themselves noticeable in the market. The fundamental source of unique value is the unique resources owned by entrepreneurs and the development strategy based on the uniqueness of these resources. Therefore, innovation is an important characteristic of business models. A business model is a comprehensive concept that does not refer to a pure profit model; however, it does not abandon the content of value acquisition. It organically combines the source of value (i.e., value creation) and value acquisition to form a balance between the two mechanisms of value generation and acquisition within an enterprise.

3) Stability. Stability means that the entrepreneur's business model has sustainable growth. For businesses equipped with comprehensive and innovative business models, it is necessary to fully stabilize the speed of market development to avoid falling behind competitors.

\section{Profile of Tencent}

Shenzhen Tencent Computer System Co. Ltd. was founded in November 1998 by Ma Huateng, Zhang Zhidong, Xu Chenye, Chen Yidan, and Zeng Liqing. Ma Huateng is the CEO and Chair of the Board of Directors. Tencent is one of the largest integrated Internet service providers in China and among the Internet companies with the largest number of service users in China. Its diverse services include the social and communication services QQ and WeChat, social networking platform QQ space, the QQ game platform under the Tencent game, portal Tencent, Tencent news client, and Internet video service, Tencent Video.

In 2004, Tencent was listed on the main board of the Hong Kong Stock Exchange (stock code: 00700). On June 20, 2018, World Brand Lab released an analysis of China's 500 Most Valuable Brands in 2018 in Beijing, which listed Tencent second. In December 2018, the Top 500 World Brands 2018 compiled by The World Brand Lab ranked the company 39th. The July 2019 release of the 2019 Fortune Global 500 listed the firm at 237th. In August 2019, Ma Huateng was listed in the top 50 of the best Boards of Directors in China 2019. Tencent Holdings Ltd was ranked 32nd among China's top 500 service companies in September 2019. In October 2019, Forbes ranked the firm number 14 in its 2019 Global Digital Economy 100 list. Tencent Holdings LTD ranked 12th in the 2019 Fortune 50 list released in October 2019.

The One Belt and One Road list of China's top 100 companies ranked the firm number 14. In November 2019, the Hurun Research Institute released the 2019 Hurun Global Top 100 Unicorns Active Investment Institutions List, and ranked Tencent second. In December of the same year, Tencent was selected as one of the top 100 firms. In December 2019, The People's Daily published a list of China's brand development index 100, ranking Tencent the 4th place[4]. 
Tencent's mission is to use the advanced technology of the Internet to improve the quality of human life. The development of Tencent QQ profoundly affected and changed the communication and living habits of hundreds of millions of Internet users. It provides a huge and convenient communication platform for users as well as various lifestyle, social service, and business application functions. It is changing people's lifestyles at an unprecedented speed, creating broader Internet application prospects.

Based on the analysis in the second chapter, Tencent's business model is analyzed and studied from the following perspectives.

\section{Profit model}

In some cases, the business model is equated with the profit model. Stewart et al.(2000) describe the business model as a systematic arrangement in which a business generates and sustains profits. Hawkins believes that enterprises can achieve business success by designing effective revenue or cost models through business models[5]. Elliot(2002) understands the business model from the capital investment perspective and points out that the business model should include investor relations, cost composition, and profit sources as much as possible[6]. From the strategy perspective, Chinese scholar Jing Linbo(2001) proposes that the business model is a strategic combination related to the firm's own strategies of finance, marketing, and operations[7].In summary, the profit model is one aspect of the business model. If the business model only considers the profit model without considering the enterprise's value model and external stakeholders, then this business model is likely to cause the failure of the enterprise.

Value creation theory

Unlike the profit model, this theory focuses on the value creation of enterprises. Makadok (2001) points out that the business model is the enterprise structure and partner network formed by enterprises for value creation, value marketing, and value promotion to generate customer relationship capital that can create and maintain value, and emphasizes that value creation includes enterprise value and customer value[8]. In their study, Afuah and Tucci(2003) describe the business model as an arrangement that can help companies prioritize their core resources, making them more competitive[9]. Chesbrough(2002) identifies the business connotation of a business model as an analytical framework that combines business ideas and technologies to produce economic output. This type of business model describes the function of enterprise value creation and value realization[10]. Zhong and Sun (2006)believe that the business model can be regarded as the operating model of an enterprise; that is, the integration of the core resources inside and outside the enterprise and continuous creation of value for the enterprise[11].

The ability to create value is the key point that enterprises should focus on. The aforementioned analysis indicates that the value creation theory truly reflects the reasonable demands of enterprises to create value for themselves and customers because value creation theory can clarify the essence of the business model.

\section{Tencent's business model}

\subsection{Analysis of Tencent's profit model}

Internet value-added services

Tencent's offers three categories of Internet value-added services: member services, community services, and game entertainment services. This specific business includes e-mail, entertainment, and information content services; dating services; casual games; and large-scale multi-user online games. Through the free to use strategy and market cultivation, the company can resist competitors through value-added services such as QQ members, QQ clothing, QQ-zone props, and ornaments. These services are the most important source of income for Tencent.

In November 2000, QQ members launched a QQ service for the elderly, wherein users pay a 10 yuan per month fee to enjoy a variety of basic QQ services outside of the additional benefits, including the selection of a QQ 
number, having information stored in the QQ server, large capacity network storage space, and several other QQ value-added services. The QQ network exclusive QQ zone offers members special tags and additional chat rooms. Tencent continues to improve the QQ membership service content to highlight the members' rich and valuable Internet experience and upscale identity. In this way, it continuously improves the stickiness of QQ for long-paying members and attracts more users to join the QQ membership group. Now, QQ memberships are Tencent's highest-earning single product.

Launched in March 2003, QQ Show allows users to choose virtual fashion and other objects at online shopping centers and design their own "virtual avatars." Apart from providing individual QQ show images for free, the fees for various QQ Show images are generally between 0.5 yuan and 3 yuan. In the fourth quarter of 2007, after Tencent launched the QQ2.0 version that supports Flash, the use of this technology improve the visuals and expressiveness of QQ, and the company moved from a pay-per-use model to a monthly fee model.

The Q-zone is one of the few Web2.0 social networking sites in the world that makes money. Unlike sites such as MySpace and Facebook, which rely on advertising revenue, Q-Zone charges by selling virtual items that dress up the QQ space.

Mobile and communication value-added services

Mobile and communication value-added services specifically include mobile chat, mobile games, mobile voice chat, mobile phone picture and ringtone download, and the former "mobile dream network," among others.

When users download or use value-added services, they pay through the intermediary operator's platform, and the operator receives the fee and then shares the payment with Tencent. This mobile and telecom value-added service set Tencent on the road to profitability.

Mobile value-added services mainly provide users with instant messaging and interconnection between QQ and mobile phones or other terminals. Mobile QQ, the earliest wireless short message service in China, was officially launched in June 2000. It allows users to connect to the QQ network through mobile phones and communicate with other QQ users in real time. The mobile QQ service is also provided through the $2.5 \mathrm{G}$ network in China, and can be used with installed client software such as a WAP browser or K-Java, Smartphone, BREW, and native code. Tencent entered agreements with some subsidiaries and branch operators of China Mobile and China Unicom to pre-install mobile QQ SMS instructions in carriers' SIM cards. Users can download the mobile QQ client software from China Mobile's WAP portal, Tencent's website, and other WAP websites.

Tencent partnered with several Chinese handset makers to pre-install mobile QQ and other client software directly into mobile phones. Most mobile QQ users use the SMS (short message service), which costs between 4.5 yuan and 5 yuan per month. In practice, no more than 2 SPs in China can get grade A, 5 SP in general, and 10 SP in general. Relying on its huge user base, Tencent can get preferential policies from operators in terms of product quantity, high-tariff billing codes, and marketing resources, which is a major factor in promoting the revenue growth of telecom value-added services in the short term. Tencent began to plan its own mobile value-added business marketing channels, including bundled promotion of QQ client-related products, promotion on $3 \mathrm{G}$ portal, and so on. The use of its own marketing channels can improve the gross profit margin of value-added services, reduce dependence on the marketing channels of operators, and further reduce the policy risk.

Online advertising

Tencent advertises online mainly through the instant messaging client software and in the QQ.com portal advertising bar to earn its network advertising revenue. With the help of QQ's huge user base, the portal website developed by Tencent QQ greatly increased its traffic and maintained a high click rate and popularity. Then, it attracted advertising placements on the Tencent portal website from various enterprises to promote their products. Consequently, its network advertising revenue will not be low. Tencent has a variety of carriers of online 
advertising that focus on targeted delivery, display, and other aspects. Tencent's advertising carrier includes the QQ client, portal website, search engine, network video, game built-in advertising (IGA), wireless WAP portal, and so on. Different advertising carriers can be aimed at different target audience groups. For example, through QQ client, Tencent can target ads to different regions and user groups with different behavioral characteristics, and in-game ads can target game user groups specifically. Some advertising carriers can show pictures and videos.

\subsection{Tencent's value creation}

\section{Target customers}

Tencent's typical user group is young and fashion-conscious users who need entertainment and to show themselves to others.

Value content

Through Tencent, users can show their own personality. At the same time, Tencent provides a large amount of entertainment content, so users can pass the time and make friends during the entertainment. Many news content sources are also an important channel for users to acquire knowledge and understand information. In addition, Tencent's online mall also meets consumers' online lifestyle demands.

Value network

Tencent's value system is three-dimensional and multidimensional. Users are exposed to Tencent's value system at different levels, though this does not affect the positioning of the framework. The underlying basic services and financial system provide the main support, though Tencent emphasizes availability and flexibility over profit.

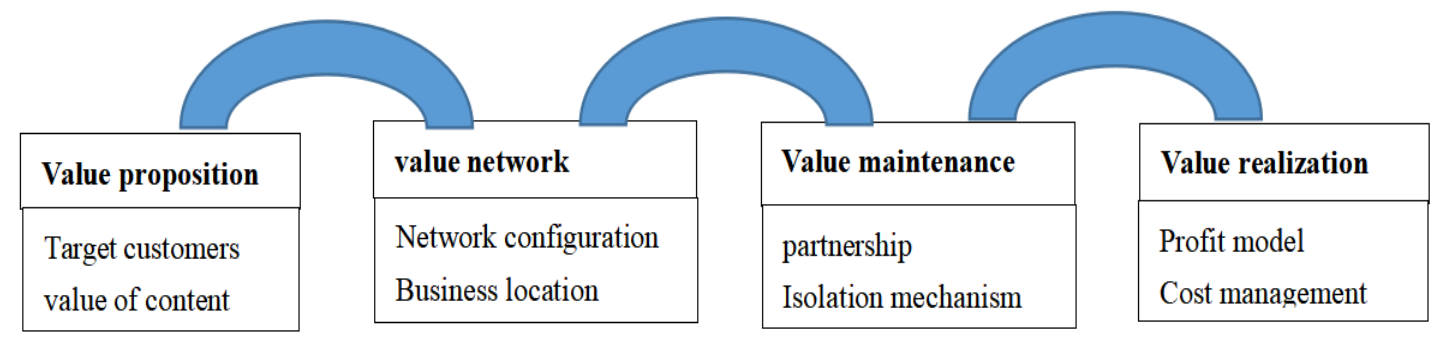

Figure 1: Business model of Tencent's "3-4-8" system

The aforementioned analysis shows that Tencent's business model consists of a "3-4-8" system, where "3" represents the contact interface, including customer value, partner value, and enterprise value. The "4" represents the constituent units of value proposition, network, maintenance, and value realization. Finally, the "8" represents the components target customers, value content, network form, business positioning, partnerships, isolation mechanism, revenue model, and cost management. In essence, the "3-4-8" composition of the business model is a three-dimensional architecture that comprehensively examines the business model in terms of the "far-middle-near" levels.

\section{Conclusion}

Tencent is one of the largest integrated Internet service providers in China and has the most service users in China. Since its establishment, Tencent adhered to a business philosophy of user value, and has always been in a state of steady and rapid development. At present, the company's main products are IM software, online games, and portal value-added products. Within a few years, relying on its own advantages and unique business model, Tencent was listed on the main board of the Hong Kong Stock Exchange in 2004. Making profits is a major goal of businesses and the key to surviving competition. However, the success of Tencent's diversified, profitable business comes largely from the company's aim to address urgent widespread social needs, provide solutions to society for free, entice price-sensitive people to use the company's products, set the consumption trend, and use 
the huge consumption trend to develop a changing and profitable model.

In 1999, Tencent put QQ software on the Internet as a free download, and the company saw a geometric growth trend in the number of users. The user base increased to more than 30 million less than two years into its development. Now, the company has nearly 400 million users; this user base has formed the foundation for Tencent to obtain other revenue. Now, the Tencent QQ user group is China's largest Internet registered user group; Tencent provides China's largest instant messaging service network. Currently, many people have a QQ number as a telephone number, e-mail address, and for other ways to contact other people. Tencent thus has created its core competitiveness and achieved a monopoly in its client channel.

Tencent is well positioned. Most of its businesses are targeted at the young; the company knows what users want and can develop appropriate products. Tencent captured the idiosyncrasies of young people who want to be different. The launch of virtual products such as QQ Show allows young people to express their personalities in the virtual world and realize their inner needs that are suppressed in real life. Thus, fashion became the basis of QQ Show, and young people use it to showcase their lifestyle. Tencent uses a profit multiplier model; that is, it gains repeated profits from the same product, feature, trademark, ability, or service. It establishes its own brands, such as in toys and clothes, which are consumed by young people. In this way, the company extends its brand effect at very low promotion cost. It thereby doubled its profits on such products.

Tencent is good at actively integrating, discovering, and utilizing the advantageous resources around it. It also takes advantage of user-based innovation, while expanding user channels or platforms so users have easy access and can improve their experiences, which improves Tencent's operations.

Today, Tencent is building its competitive advantage step by step, constantly exploring new areas, such as artificial intelligence, driverless cars and so on.As a giant enterprise with strong innovation ability in China, it established a platform for many local enterprises and made steady progress in today's increasingly fierce competition.

\section{Acknowledgment}

This work was supported by the Ministry of Education of the Republic of Korea and the National Research Foundation of Korea(NRF-2019S1A5A8038785)

\section{Reference}

1. Lin Song, Zhou Weizhong. (2008) Rethinking Business Model [J]. Enterprise Management, 2008, (6) :P33-35.

2. 2.Chen xiumei.(2016). innovation path analysis of business model based on conceptual connection mechanism -- taking Tencent WeChat payment as an example, operation and management, October, P58

3. Ji huisheng.(2015). Internet enterprise business model analysis framework - based on the case study of Tencent company business era, issue 29.P60

4. 4.Tencent Baidu Baike: https://baike.baidu.com/item/\%E8\%85\%BE\%E8\%AE\%AF

5. David W. Stewart\& Qin Zhao(2000)."Intemet marketing, business models, and public policy", ournal of Public Policy \& MarketingVol. p 287-296

6. 6.Steve Elliott.(2002) Electronic Commerce: B2c Strategies and Models,February (book)

7. 7.Jing Linbo.(2001).B2B business model and its value evaluation, commercial economics.P18-22

8. 8.Makadok .Richard.(2001). Toward a Synthesis ofthe Resource-Based and Dynamic Capability Views ofRent Creation.Strategic Management Joumal, P387-402

9. 9.Allan Afuah, Christopher L Tucci.(2003).Internet business models and strategies: Text and cases,McGraw-Hill.P5-11

10. 10.Chesbrough.H\& RosenbIoom .R.S.(2002).The role ofthe business model capturing value from 
innovation: evidence from Xerox Corporation's technology spin-off companies.Industrial and Corporate Change.P529-555

11. 11.Zhong.G.S\& Sun.X.J.(2006).Six perspectives and Integration of business Model research,Economic research.27(2),P120-124

12. 12.Chang, Y. S., Jeon, S.M., \& Shamba, K., (2019). Speed of Catch-up and Digital Divide: A Study of Three Information Communication Technologies for 44 African Countries. Journal of Global Information Technology Management, 23(3), 217-234

13. Choi,S. B., Lee, W. R., \&Kang, S. W. (2020). Entrepreneurial Orientation, Resource Orchestration Capability, Environmental Dynamics and Firm Performance: A Test of Three-Way Interaction, 12(13), 5415

14. Jung, K.B, Kang, S. W., \& Choi, S. B.(2020). Empowering Leadership, Risk-Taking Behavior, and Employees' Commitment to Organizational Change: The Mediated Moderating Role of Task Complexity. Sustainability, 12(6), 2340.

15. Collet, C., Tozetto, A. V. B., Iha, T., do Nascimento, J. V., Falcão, W. R., \& Milistetd, M. (2019). Dynamic Elements of Sports Development: Perceptions of Basketball Coaches. Revista de psicología del deporte, 28(3), 79-85. 